\title{
Reduction of Selenate in contact with Pyrite [100]: a DFT ab-initio study
}

\author{
VIVIEN RAMOTHE ${ }^{1}$, PAULINE SIMONNIN ${ }^{2}$, BENJAMIN
} GILBERT $^{3}$, KEVIN ROSSO $^{2}$ AND LAURENT CHARLET ${ }^{4}$

${ }^{1}$ ISTerre -CNRS

${ }^{2}$ Pacific Northwest National Laboratory

${ }^{3}$ Lawrence Berkeley National Lab

${ }^{4}$ ISTerre, CNRS

Presenting Author: ramothe.vivien@gmail.com

The radioactive isotope ${ }^{79} \mathrm{Se}$ is a key mobile fission product for the disposal of spent fuel and high-level radioactive waste. One of the environmental issues regarding Se is related to a very narrow concentration range between its nutritional deficiency and toxicity. Therefore, its mobility, fate, and concentration in the environment have important implications for human health and the growth of animals and plants. It is a redox-sensitive radionuclide and its solubility is largely controlled by oxidation state. Selenate prevail as mobile aqueous oxyanions, while the oxidation states 0 , -I, and -II prevail as solids with low solubility. Pyrite is the most widely occurring sulfide mineral in geological environment and is known to buffer reducing conditions in clay formation. Numerous studies have revealed that pyrite can reduce and immobilize redox-sensitive radionuclides such as $\mathrm{Se}$ and others. For pyrite interaction with aqueous Se(IV), previous research focused on the identification of selenium species on the pyrite surface. But Se speciation on the pyrite surface should be a function of environmental parameters. The mechanism involved in the adsorption and charge transfer between Selenate ions $\left(\mathrm{SeO}_{4}\right)^{2-}$ and pyrite is yet to be understood. Thus, we performed ab-initio calculations based on density functional theory (DFT) to provide insight into this interfacial reaction. We describe the charge transfer between mineral surface and Se(VI) species. We chose to study pyrite [100] with and without dangling disulfide. We also investigate selenate ions in the gas phase and in water. This is a perfectly symmetric tetrahedral ion which reduces the number of orientations available during the adsorption on mineral surfaces. Finally we combined the ions and the pyrite surfaces to observe the surface sulfur substitution of selenate oxygen atoms, and thus the reaction pathway that leads to reduction of selenate in contact with pyrite. 